\title{
Clinical and histological challenge in the differential diagnosis of diffuse alopecia: female androgenetic alopecia, telogen effluvium and alopecia areata - Part II \\ Desafio clínico e histológico no diagnóstico diferencial de alopecia difusa: alopecia androgenética, eflúvio telógeno e alopecia areata - Parte II
}

\author{
Betina Werner $^{1}$
}

\author{
Fabiane Mulinari-Brenner ${ }^{2}$
}

\begin{abstract}
Diffuse alopecia is mainly caused by telogen effluvium, diffuse androgenetic alopecia (femalepattern hair loss) and diffuse alopecia areata. Differential diagnosis between the three disorders may be difficult in several occasions. In this second part of our study, chronic telogen effluvium and diffuse alopecia areata are discussed in detail, including clinical, dermoscopic and histological aspects. A flowchart presents a practical and objective differential diagnostic approach to diffuse alopecia.

Keywords: Alopecia; Alopecia areata; Biopsy; Dermoscopy; Histology

Resumo: A alopecia difusa tem como principais causas eflúvio telógeno, alopecia androgenética difusa (alopecia androgenética de padrão feminino) e alopecia areata difusa. Em muitas ocasiões o diagnóstico diferencial entre as três entidades é difícil. Na segunda parte deste artigo se discute em mais detalhes as características clínicas, dermatoscópicas e histológicas do eflúvio telógeno crônico e da alopecia areata difusa. Uma maneira prática e objetiva de abordagem diagnóstica da alopecia difusa é apresentada através de um fluxograma.

Palavras-chave: Alopecia; Alopecia em áreas; Biópsia; Dermoscopia; Histologia
\end{abstract}

\section{INTRODUCTION}

Diffuse alopecia is a common complaint and a major challenge in the practice of dermatology, especially when it affects women. Female androgenetic alopecia (FAA) or female-pattern hair loss, chronic telogen effluvium (TE), and diffuse alopecia areata (AA) are its three main causes. It is often difficult to distinguish one from the other, and clinical data, laboratory findings, physical examination, propaedeutic procedures, and biopsy may be needed for a definitive diagnosis.
This article, which was divided into two parts, aims to highlight the clinical, dermoscopic, and histological differences between TE, FAA, and diffuse AA in a practical and objective manner. In the first part, the authors addressed diffuse alopecia in general and FAA. ${ }^{1}$ In this second part, TE and diffuse AA are discussed. Moreover, the three causes of diffuse alopecia are compared in a flowchart and a diagnostic approach based on physical examination, clinical, and dermoscopic findings is suggested.

Received on 16.04.2011.

Approved by the Advisory Board and accepted for publication on 23.05.2011.

* Work conducted at the Pathology and Dermatology Services, Clinics Hospital (Hospital de Clinicas - HC), Federal University of Parana (Universidade Federal do Parana - UFPR); Diagnose (private practice of Surgical Pathology and Dermatopathology); and Cepelle (Center Specialized in the Skin - private practice of Dermatology) - Curitiba (PR), Brazil.

Conflict of interest: None

Financial funding: None

PhD - Dermatopathologist with a diploma from the International Society of Dermatopathology - MSc in Clinical Surgery (with concentration in Surgical Pathology), Federal University of Parana (UFPR). PhD in Child and Adolescent Health (with concentration in Dermatopathology), Federal University of Parana (UFPR) - Professor at the Department of Pathology - Clinics Hospital (Hospital de Clínicas), Federal University of Parana (HC-UFPR) - Curitiba (PR) Brazil. MSc - Dermatologist. MSc in Internal Medicine, Federal University of Parana (UFPR). Professor of Dermatology, Clinics Hospital (Hospital de Clínicas), Federal University of Parana (HC-UFPR) - Curitiba (PR), Brazil. 


\section{History, physical examination and laboratory fin- dings}

\section{Telogen effluvium}

TE may begin at any age with a sudden increase in hair loss and maintenance of the frontal hair density. ${ }^{2}$ Surgery, fever, childbirth, iron deficiency, stress, chronic diseases, and dietary changes are factors commonly associated with the disorder. ${ }^{3} \mathrm{~A}$ time interval of two to three months between the triggering factor and the onset of the disorder is most commonly observed, and it lasts from four to six months in its acute forms. It is suggested that early entrance in the telogen phase is triggered by the inciting event, causing the habitual asynchrony in normal hair loss to go through a synchronic shedding period.

Dietary restrictions, especially protein and iron restrictions, should be excluded, and vegetarians are a risk group for TE. ${ }^{4}$ An evaluation of the menstrual cycle may identify hyperpolymenorrhagia as the cause of iron deficiency. Weight changes may be associated with thyroid disorders. Sudden weight loss or dietary restriction, as it occurs after bariatric surgery, may lead to TE. Initiation or cessation of drug therapy or changes in drug dosage, such as antidepressants, contraceptives, and poly-vitamins, must be observed. ${ }^{3}$

Chronic forms of TE may have shedding periods longer than six months, especially when the triggering factors are persistent or multiple. A recent study identified a shortening of the anagen phase of the follicle as a possible cause of chronic forms of TE, suggesting a growth period of 18 months on average (instead of four to six years). ${ }^{2}$ Basic laboratory investigation includes TSH and ferritin measurement to exclude two of the most common causes of TE: iron deficiency (it is most often not enough to cause changes in the blood count) and hypothyroidism. Ferritin measurement is the test that best reflects a bone marrow aspirate and should be higher than $60 \mathrm{ng} / \mathrm{dl}$. Total iron-binding capacity and saturation index appear to be less important. ${ }^{5}$ Ferritin measurement has always been controversial, since there was no improvement in cases of TE treated with iron supplementation up to levels of $20 \mathrm{ng} / \mathrm{dl}$, although values above $10 \mathrm{ng} / \mathrm{dl}$ are considered normal from a laboratory point of view. ${ }^{6}$ Ferritin levels below $60 \mathrm{ng} / \mathrm{mL}$ with normal erythrocyte sedimentation rate (ESR) present high specificity and predictive value (>90\%) for iron deficiency. ${ }^{5}$ It is important to emphasize that ferritin is an acute-phase protein, likely to undergo changes due to inflammatory and infectious processes in a nonspecific way. In these cases, interpretation associated with ESR is required. In women with iron deficiency, correction of ferritin levels reduced the number of scalp telogen hairs in more than $60 \% .{ }^{4}$ Other tests may be needed according to the patient's clinical findings.
The light hair pull test is positive during the active phase of the disease, and large amounts of hair (more than 100 hairs) are shed daily. The patient often brings shed hair samples to the office (Figure 1). A microscopic evaluation of hairs shed reveals hairs of homogeneous thickness and in the telogen phase only. A frequent feature of TE is presence of hair loss in other parts of the body, including eyebrows and genitals, which generally present faster recovery than the scalp. ${ }^{3}$ After the phase of acute hair loss, two to four months after elimination of the trigger, it is possible to note normal homogeneous growth - approximately $1 \mathrm{~cm}$ per month.

\section{Diffuse alopecia areata}

In diffuse AA, the typical "patches" of hair loss do not exist, and hair thinning is subtly distributed throughout the scalp. The debate over the definition of the condition began in 1987, when a form of noninflammatory anagen effluvium was described as a differential diagnosis of TE and called AA incognita. Hypothetically, the condition developed in individuals with a large number of telogen hairs on the scalp. In these patients, who had fewer anagen hairs at a given time, an external factor would hinder growth during the period of higher mitotic activity of the anagen phase in a diffuse manner. ${ }^{7}$ Later, Sato-Kawamura et al. described a group of women with total diffuse AA with a favorable prognosis, fast recovery, and called it "diffuse and total alopecia." ${ }^{8}$ Other authors have observed the same characteristics in men. ${ }^{9}$

In diffuse $\mathrm{AA}$, women seem to be the most affected group according to the literature. ${ }^{10}$ The patient's complaint is usually diffuse hair loss with abrupt or progressive onset associated with periods of psychological stress or systemic diseases. ${ }^{11}$ It is known that

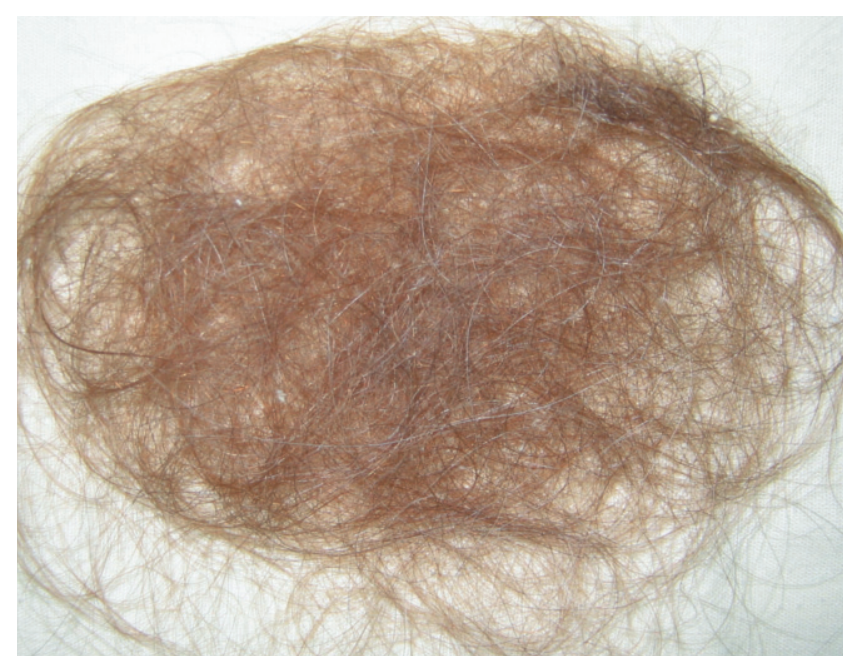

Figure 1: Telogen effluvium. Sample of spontaneous hair loss brought by the patient to the doctor's office 
$60 \%$ of patients have their first patch of alopecia before the age of 20 in typical AA, which may occur in diffuse AA. ${ }^{11}$ Up to $20 \%$ of patients with AA have family members affected by the condition, and the incidence of autoimmune diseases in the family is more common than in the general population. ${ }^{11}$

Nail changes, association with thyroiditis, vitiligo, atopic syndrome and Down syndrome are frequent in AA. ${ }^{11}$ In the diffuse forms described in the literature and in the cases observed by the authors, the frequency of nail changes is not significant. ${ }^{10}$ Positive anti-thyroglobulin and anti-thyroperoxidase antibodies, with no changes in the thyroid function, and ferritin levels below $70 \mathrm{ng} / \mathrm{dl}$ have been reported. ${ }^{10}$

When parting the hair on the scalp, no predilection for involvement of the frontal area is observed, and there may be similar or greater hair thinning in the occipital scalp. More prominent thinning in retroauricular areas seems to indicate diagnosis of diffuse AA (Figure 2). The light hair pull test is positive, and there are usually reports of more than 100 hairs shed daily. A microscopic evaluation of the hairs shed reveals dystrophic anagen hairs or "pencil point" hairs (corresponding to normal-looking shafts tapered at the proximal end) among telogen hairs. These findings easily rule out TE and FAA. ${ }^{12}$

\section{DERMOSCOPY}

\section{Telogen effluvium}

In general, there is no variation in the diameter of the hair shafts, even in the chronic forms. ${ }^{2} \mathrm{~A}$ variation of up to $20 \%$ is acceptable, and some follicular ostia may be empty or present vellus hairs. ${ }^{13}$ Dermoscopy generally distinguishes TE from FAA, with careful examination of the frontal area of the

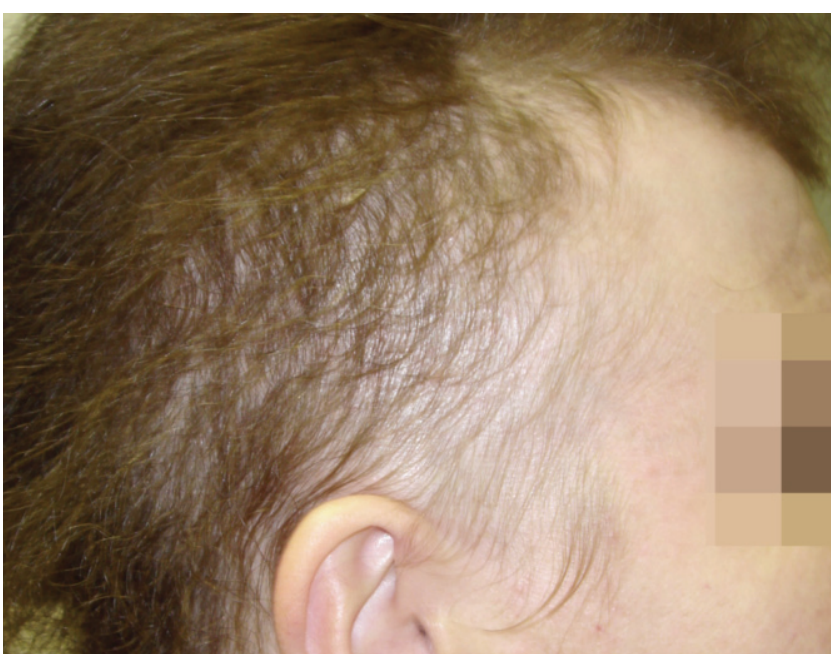

Figure 2: Alopecia areata. In the diffuse form, in general, there is no central hair thinning, and other areas may be more affected, as in this case of temporal and retroauricular predominance scalp, but there may be a combination of both diseases, leading to inconsistency of the findings.

\section{Diffuse alopecia areata}

Dermoscopy in diffuse AA has been much discussed, and many experts consider it the best way to diagnose the condition. ${ }^{10}$ The characteristic inflammatory process that affects the follicle may cause the shaft to break and allow dermoscopic visualization of black dots (or cadaverous hair) as well as of broken hairs, besides the traditional "exclamation mark" hair, especially in the periphery of active plaques (Figures $3 \mathrm{~A}$ and $3 \mathrm{~B}$ ). In the diffuse forms of AA, they may be isolated and distributed in a sparse manner, which is often revealed after careful dermoscopic examination. Recently, hairs similar to "exclamation marks" have also been identified in trichotillomania. ${ }^{14}$ Groups of vellus hair are identified in initial regrowth, and thinner and shorter $(10 \mathrm{~mm})$ shafts with little pigmentation can be seen among other structures. ${ }^{15}$

Yellow dots were initially described as pathognomonic of diffuse AA, being highly emphasized in the diagnosis of the diffuse form ("incognita") by Tosti et al., but they have also been observed in other conditions and even considered a major diagnostic criterion for FAA (Figure 3C) . ${ }^{10,16}$ Inui et al. published a study involving 300 patients with AA and found yellow dots in percentages ranging from $57 \%$ to $78 \%$ of patients, including many different forms of the disease. ${ }^{17}$ Inui, Nakajima and Itami noticed yellow dots in male androgenetic alopecia (26\%) and female androgenetic alopecia (10\%), correlating them in a speculative way (without histological confirmation) with the increased volume of the sebaceous gland. ${ }^{18}$

At least one of the findings discussed above must be found in order to consider the dermoscopic diagnosis of diffuse AA: black dots, exclamation mark hairs, broken hairs, or yellow dots. ${ }^{14}$ Observation of groups of vellus hair and yellow dots appears to be more sensitive for the diagnosis of diffuse AA, whereas black dots, tapered (pencil point) hair, or broken hair are more specific. ${ }^{15}$

\section{FLOWCHART}

The flowchart suggests a logical sequence for the diagnostic approach of cases of diffuse alopecia based on physical examination, clinical, and dermoscopic data (Figure 4). In cases of ambiguous findings, histological analysis of the scalp should be included, for it might facilitate the correct diagnosis.

\section{MICROSCOPIC ASPECTS}

A scalp biopsy in diffuse alopecia is recommended when the clinical and dermoscopic findings are not enough to differentiate the three conditions. 

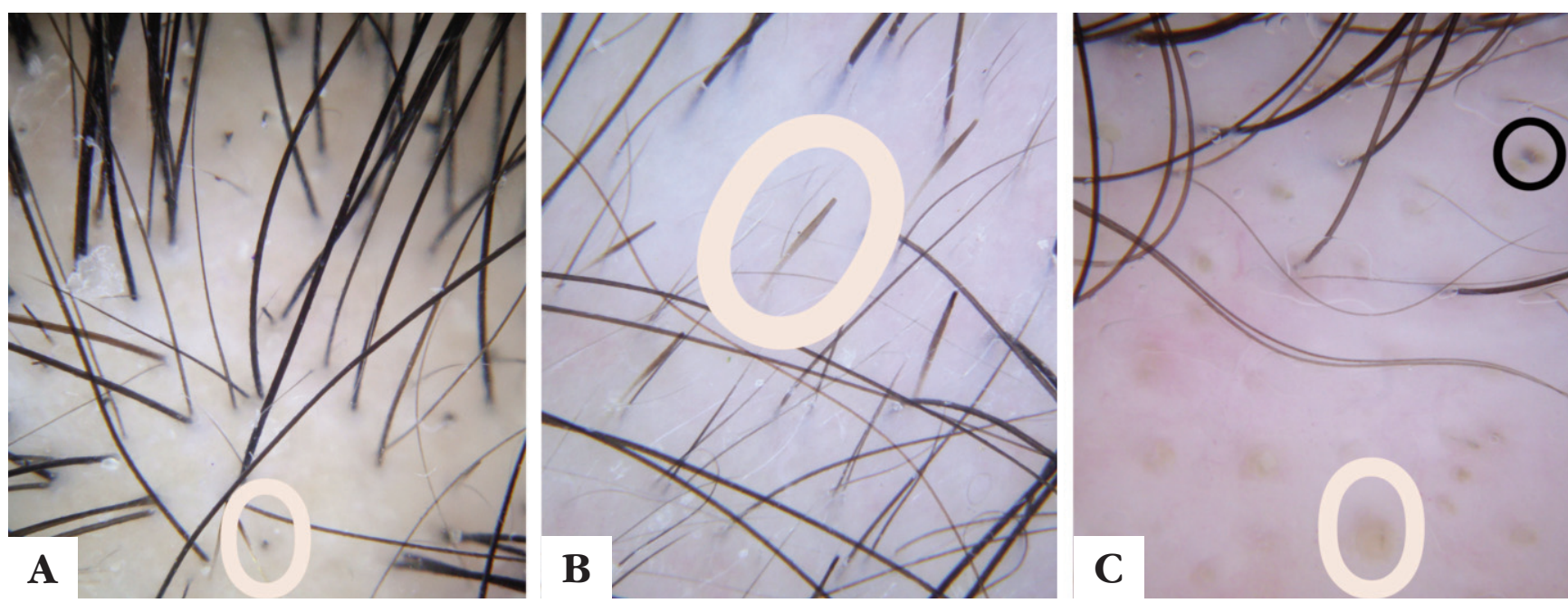

FIGURE 3: Dermoscopic aspects in alopecia areata. A. Black dots (circle) and broken hairs in the active phase of the disease. B. Exclamation mark hairs, with distal ends wider than proximal ends (circle). C. Multiple yellow dots - in this case, the association with black dots

(black circle) favors the diagnosis of AA
Guidelines on the best way to obtain a scalp specimen for investigation of diffuse alopecia have already been discussed, and the analysis of histological cross sections of diffuse alopecia has been discussed in general terms in Part I of this study. ${ }^{1,19}$

\section{Telogen effluvium}

The total number of follicles and the terminal:vellus $(\mathrm{T}: \mathrm{V})$ ratio basically do not change in chronic TE (normal 7:1). However, there may be an increase in telogen count (TC) (more than 6\%). ${ }^{20-24}$ No variation in the diameter of the hair shafts is observed, and the sebaceous glands show volumes similar to those observed in normal scalp. Usually, there is no inflammatory component, and trichomalacia is not found. Follicular fibrous tracts are rarely seen.

The main differential diagnosis of chronic TE is FAA in its initial phase, as discussed in Part I (1). In summary, a T:V ratio close to 7:1 is indicative of chronic TE, and a T:V ratio $<4: 1$ is characteristic of FAA. ${ }^{21,22,2427}$ Values between $4: 1$ and 7:1 may not define the diagnosis, and the number of telogen follicles and/or telogen germinal units may be increased in both conditions. Multiple samples (to compare the parietal and occipital regions, for example) collected at different moments may be necessary to distinguish between the two conditions.

\section{Alopecia areata}

AA has three histological stages: acute, subacute and chronic. ${ }^{20,21,28}$ Each histological stage presents some peculiar characteristics, but the total number of hair follicles does not change in any of these stages.

The acute stage corresponds to recent onset of the disease or to the disorder with fast progression of the area of alopecia. The first histological sign of the disease is a lymphocytic infiltrate around the bulb of the terminal hair located in the hypodermis. Sperling points out other early histological findings of AA, such as necrosis of matrix cells in the hair bulb and presence of remains of melanin within the follicular epithelium as a result of necrosis of melanocytes (Figure 5A). ${ }^{20} \mathrm{Ihm}$ et al. showed that the earliest histological change in apparently normal regions close to areas with recent onset of alopecia is destruction of the integrity of the bulbar epithelium, with transformation of the rounded shape of the hair bulb into a golf-club shape. ${ }^{29}$

The subacute stage does not correlate well with a specific clinical presentation or evolution of the disease. The number of catagen follicles increases. As the disease progresses, the number of telogen follicles or telogen germinal units also increases (in some cases, reaching $100 \%$ of the hair follicles in the sample) (Figure 5B). In the authors' experience, the telogen germinal units in AA may present some distortion or dystrophy (Figure 5C). The number of follicular tracts also becomes prominent, and they may have a lymphocytic inflammatory infiltrate around or inside them (Figure 5D). It is important to emphasize that the characteristic peribulbar inflammation in AA may be absent in this stage. ${ }^{20,21,23,28}$ According to Elston et al., 38\% of cases of AA do not present this type of inflammatory infiltrate, and eosinophils are observed in $18 \%$ of cases. In this stage, signs of trichomalacia may be found. ${ }^{30}$

The chronic stage corresponds to the disease with well-established and long-lasting areas of alopecia and also to well-established cases of alopecia totalis and universalis. There is an inversion of the T:V 


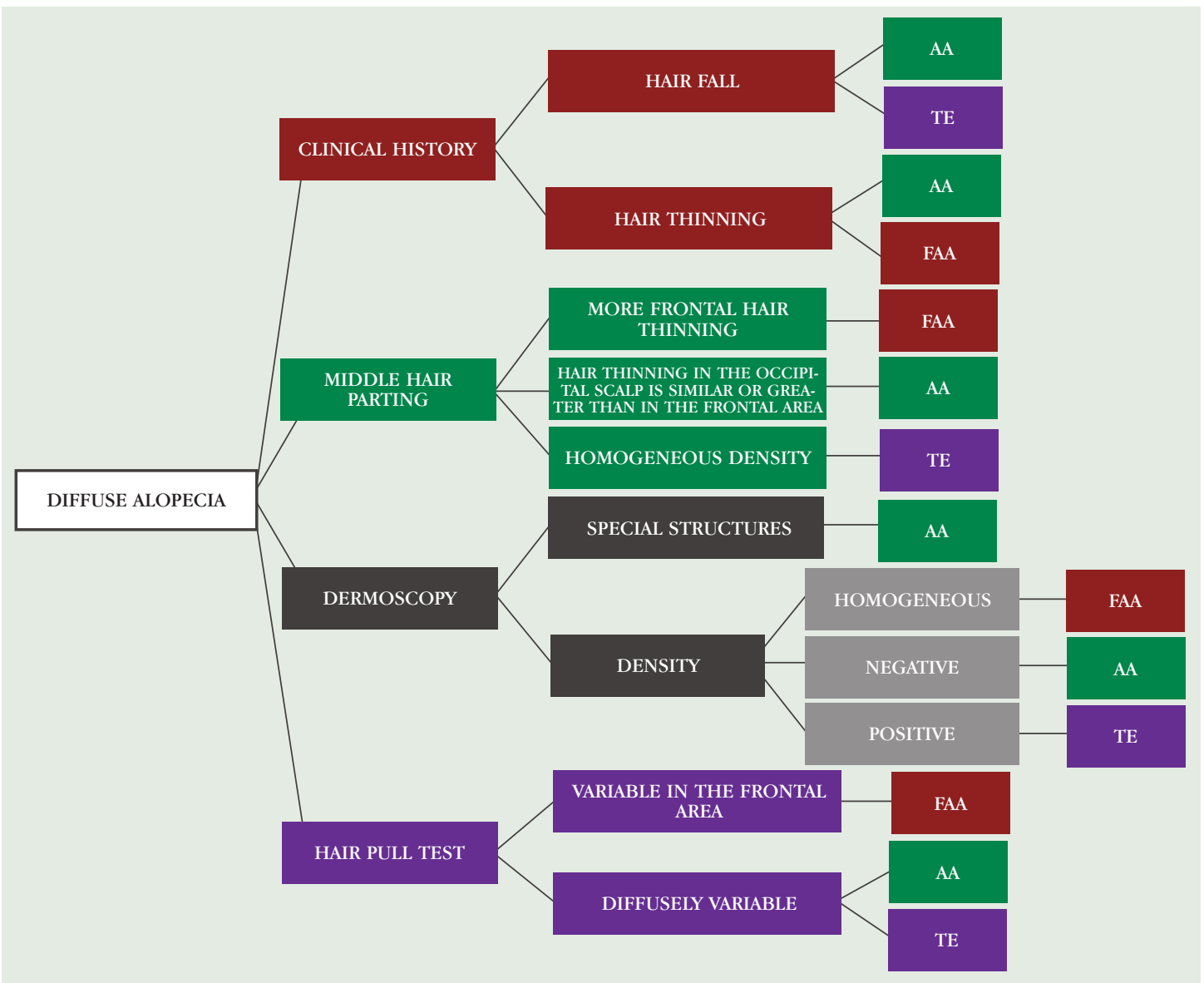

FIGURE 4: Flowchart on diffuse alopecia Diagnostic approach according to physical examination, clinical, and dermoscopic findings in diffuse alopecia. * Special structures include cadaverous hairs, exclamation mark hairs, and multiple yellow dots ratio, with emergence of a large number of miniaturized hairs, similar to vellus hairs. The ratios become similar to those found in FAA. Sperling calls those hairs "nanogen" and presents some subtle morpholo- gical characteristics that differentiate them from real vellus hairs (for instance, absence of the hair shaft in the follicular channel). ${ }^{20}$ Lymphocytes can be found around the bulbs of miniaturized follicles located in
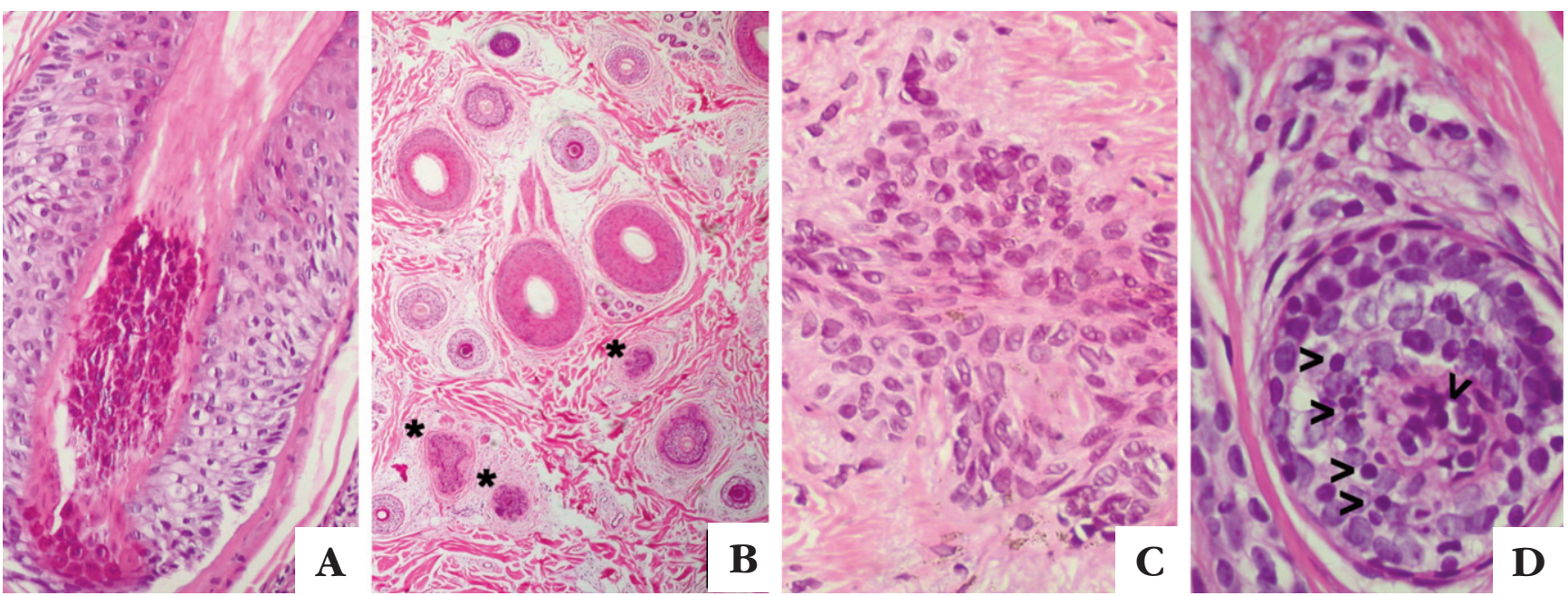

FIgURE 5: Microscopic aspects of alopecia areata. A. Terminal follicle with necrosis of matrix cells in the bulb (early finding in the acute stage of AA). HE, 200x objective. B. Histological cross section of AA at the dermo-hypodermal transition level. Presence of many miniaturized follicles and three telogen germinal units $(*)$. HE, 40x objective. C. Histological cross section of a distorted telogen germinal unit with melanophages. HE, 400x objective. D. Miniaturized hair follicle in AA with lymphocytes within the bulb (arrowheads). HE, 400x objective 
the mid/superficial dermis or within follicular fibrous tracts, sometimes together with melanophages. When $\mathrm{AA}$ is long lasting, the hair follicles may acquire extreme degrees of miniaturization and lose the ability to return to a normal anagen phase (permanent alopecia). ${ }^{20,23}$

Fanti et al. noticed no histological difference in 12 of 14 patients with AA who did not respond to sensitizing therapies. ${ }^{31}$ The histological aspects corresponded to the chronic and permanent/scarring phase of AA in only two cases, which could explain why there was no response to treatment. Interestingly, these were the two patients who had the disease for only one year (one with alopecia totalis and the other with alopecia universalis). This shows that AA is a cyclic disease, and the histological findings may reflect the stage in which the area with alopecia is at the time of biopsy, not necessarily identifying the stage of evolution of the disease in general.

The authors of this paper had the opportunity to observe two biopsies of yellow dots guided by dermoscopy in patients with AA. Follicular infundibula and/or dilated ducts of sebaceous glands were observed, but without a compact keratin plug, as observed in comedones. These characteristics were best observed in conventional histological sections (longitudinal) (Figure 6).

\section{CONCLUSION}

The distinction between chronic TE and initial FAA may depend on multiple biopsies to improve sampling and/or on the evolution of the disease so that it is completely expressed clinically and histologically. In

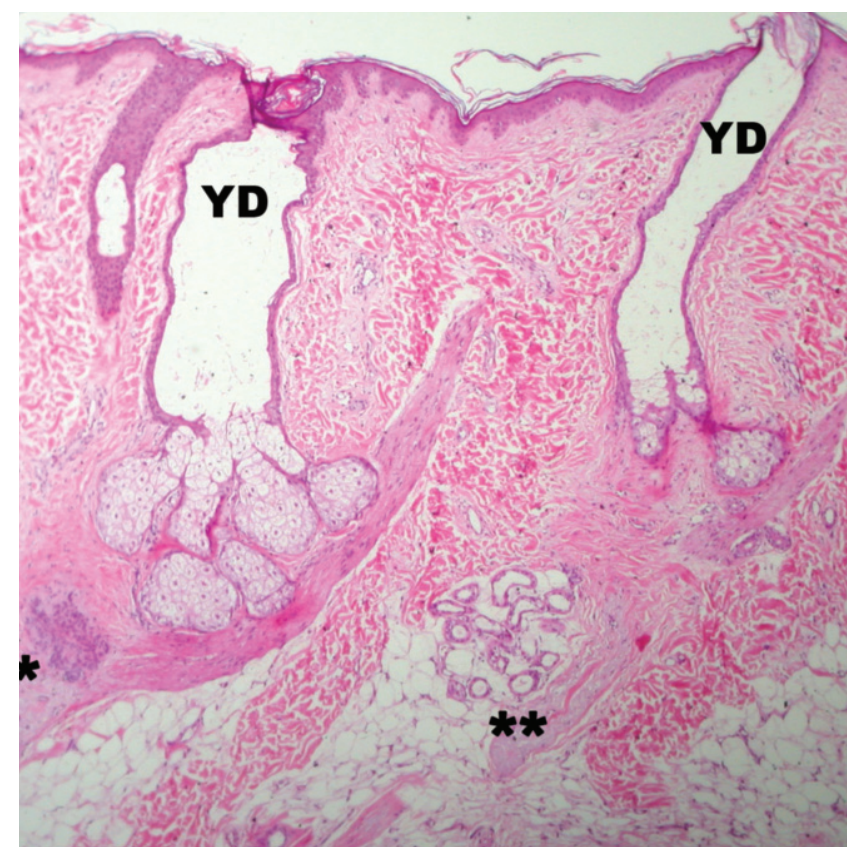

FigURE 6: Microscopic aspects of alopecia areata. Longitudinal histological section of AA with two dilated follicular infundibula that correspond to the yellow dots (YD) observed on dermoscopy. Presence of a telogen germinal unit (*) and a follicular fibrous tract $(* *)$. HE, $100 x$ objective

TE, there are few significant histological changes. Diffuse AA may present a diagnostic challenge when the peribulbar inflammatory infiltrate is not detected. The yellow dot revealed by dermoscopy reflects dilation of the follicular infundibulum. 


\section{REFERENCES}

1. Werner B, Mulinari-Brenner F. Clinical and histological challenge in the differentia diagnosis of diffuse alopecia: female androgenetic alopecia, telogen effluvium and alopecia areata - Part I. An Bras Dermatol. 2012;87:742-7.

2. Gilmore $\mathrm{S}$, Sinclair R. Chronic telogen effluvium is due to a reduction in the variance of anagen duration. Australas J Dermatol. 2010;51:163-7.

3. Mulinari-Brenner F, Bergfeld W. Entendendo o Eflúvio Telógeno. An Bras Dermatol. 2002;77:87-94.

4. Rushton DH. Nutritional factors and hair loss. Clin Exp Dermatol. 2002;27:396-404

5. Ong KH, Tan HL, Lai HC, Kuperan P. Accuracy of various iron parameters in the prediction of iron deficiency in an acute care hospital. Ann Acad Med Singapore. 2005;34:437-40.

6. Sinclair R. There is no clear association between low serum ferritin and chronic diffuse telogen hair loss. Br J Dermatol. 2002;147:982-4.

7. Rebora A. Alopecia areata incognita: a hypothesis. Dermatologica. 1987;174:214-8.

8. Sato-Kawamura M, Aiba S, Tagami H. Acute diffuse and total alopecia of the female scalp. A new subtype of diffuse alopecia areata that has a favorable prognosis. Dermatology. 2002;205:367-73.

9. Lew BL, Shin MK, Sim WY. Acute diffuse and total alopecia: a new subtype of alopecia areata with a favorable prognosis. J Am Acad Dermatol. 2009;60:85-93.

10. Tosti A, Whiting D, Iorizzo M, Pazzaglia M, Misciali C, Vincenzi C, et al. The role of scalp dermoscopy in the diagnosis of AA incognita. J Am Acad Dermatol. 2008;59:64-7

11. Alkhalifah A, Alsantali A, Wang E, McElwee KJ, Shapiro J. AA update: part I. Clinical picture, histopathology, and pathogenesis. J Am Acad Dermatol. 2010;62:177-88.

12. Quercetani R, Rebora AE, Fedi MC, Carelli G, Mei S, Chelli A, et al. Patients with profuse hair shedding may reveal anagen hair dystrophy: a diagnostic clue of alopecia areata incognita. J Eur Acad Dermatol Venereol. 2011;25:808-10.

13. Tosti A, Torres F. Dermoscopy in the diagnosis of hair and scalp disorders. Actas Dermosifiliogr. 2009;100 Suppl 1:114-9.

14. Abraham LS, Torres FN, Azulay-Abulafia L. Dermoscopic clues to distinguish trichotillomania from patchy alopecia areata. An Bras Dermatol. 2010;85:723-6.

15. Inui S, Nakajima T, Itami S. Significance of dermoscopy in acute diffuse and tota alopecia of the female scalp: review of twenty cases. Dermatology. 2008;217: 333-6.

16. Rakowska A, Slowinska M, Kowalska-Oledzka E, Olszewska M, Rudnicka L. Dermoscopy in female androgenic alopecia: method standardization and diagnostic criteria. Int J Trichology. 2009;1:123-30

17. Inui S, Nakajima T, Nakagawa K, Itami S. Clinical significance of dermoscopy in alopecia areata: analysis of 300 cases. Int J Dermatol. 2008;47:688-93.

18. Inui S, Nakajima T, Itami S. Scalp dermoscopy of androgenetic alopecia in Asian people. J Dermatol. 2009:36:82-5
19. Werner B. Biópsia de pele e seu estudo histológico. Por quê? Para quê? Como? Parte II. An Bras Dermatol. 2009;84:507-13.

20. Sperling L. An atlas of hair pathology with clinical correlations. 1st ed. New York: The Parthenon Publishing Group; 2003.

21. Stefanato CM. Histopathology of alopecia: a clinicopathological approach to diagnosis. Histopathology. 2010;56:24-38

22. Whiting DA. Chronic telogen effluvium: increased scalp hair shedding in middleaged women. J Am Acad Dermatol. 1996;35:899-906

23. Sellheyer K, Bergfeld WF. Histopathologic evaluation of alopecias. Am J Dermatopathol. 2006;28:236-59.

24. Sinclair R. Chronic telogen effluvium: a study of 5 patients over 7 years. J Am Acad Dermatol. 2005;52(2 Suppl 1):12-6.

25. Ekmekci TR, Sakiz D, Koslu A. Occipital involvement in female pattern hair loss: histopathological evidences. J Eur Acad Dermatol Venereol. 2010;24:299-301.

26. Sinclair R, Jolley D, Mallari R, Magee J. The reliability of horizontally sectioned scalp biopsies in the diagnosis of chronic diffuse telogen hair loss in women. J Am Acad Dermatol. 2004;51:189-99.

27. Sinclair R. Chronic telogen effluvium or early androgenetic alopecia? Int $J$ Dermatol. 2004;43:842-3.

28. Whiting DA. Histopathologic features of alopecia areata: a new look. Arch Dermatol. 2003;139:1555-9.

29. Ihm CW, Hong SS, Mun JH, Kim HU. Histopathological Pictures of the Initial Changes of the Hair Bulbs in alopecia areata. Am J Dermatopathol. 2004;26:249-53.

30. Elston DM, McCollough ML, Bergfeld WF, Liranzo MO, Heibel M. Eosinophils in fibrous tracts and near hair bulbs: a helpful diagnostic feature of AA. J Am Acad Dermatol. 1997;37:101-6

31. Fanti PA, Tosti A, Bardazzi F, Guerra L, Morelli R, Cameli N. Alopecia areata. A pathological study of nonresponder patients. Am J Dermatopathol 1994:16:167-70.

How to cite this article: Werner B, Mulinari-Brenner F. Clinical and histological challenge in the diagnosis of diffuse alopecia: female androgenetic alopecia, telogen effluvium and alopecia areata - Part II. An Bras Dermatol. 2012;87(6):884-890 